\title{
Application of auxological methods, including dental age estimation, in the assessment of delayed puberty in girls in gynecological practice
}

\author{
Magdalena Durda-Masny' ${ }^{1}$ Grazyna Jarzabek-Bielecka², Justyna Opydo-Szymaczek², \\ Agnieszka Przystanska ${ }^{4}$, Malgorzata Mizgier ${ }^{5}$, Witold Kedzia² \\ ${ }^{1}$ Department of Human Biological Development, Institute of Anthropology, Faculty of Biology, Adam Mickiewicz University, \\ Poznan, Poland \\ ${ }^{2}$ Division of Developmental Gynecology and Sexology, Department of Perinatology and Gynecology, \\ Poznan University of Medical Sciences, Poland \\ ${ }^{3}$ Department of Pediatric Dentistry, Poznan University of Medical Sciences, Poland \\ ${ }^{4}$ Department of Temporomandibular Disorders, Division of Prosthodontics, Poznan University of Medical Sciences, Poland \\ ${ }^{5}$ Department of Morphological and Health Sciences, Dietetic Division, Faculty of Physical Culture in Gorzow Wielkopolski, \\ Poznan University of Physical Education, Poland
}

\begin{abstract}
Developmental gynecology uses methods practiced in auxology - the science of human ontogenetic development. An important and jointly used concept in gynecology and auxology is the concept of developmental age, which, unlike calendar age, is a measure of the biological maturity of the organism, indicating the stage of advancement in the development of certain features or body systems. Developmental age assessment methods include: a) morphological (somatic) age - body height and weight, b) secondary sex characteristics — breast in girls, genitalia (penis and testes) in boys, and pubic hair in both sexes, c) bone age - hand and wrist x-ray, and d) dental age. An important marker of developmental age is also age at menarche, treated as a late indicator of puberty in girls. All of these methods are useful in the context of assessing regularity and disorders of puberty, such as delayed puberty. The paper discusses developmental age assessment methods that can be used to diagnose delayed puberty as well as the causes of delayed puberty in girls. It should be emphasized that in assessing the process of physical development of a given individual, the cooperation of specialists in the field of developmental gynecology, pediatrics, auxology, dentistry, endocrinology, and dietetics would be the most desirable. Key words: developmental age; delayed puberty; girls
\end{abstract}

Ginekologia Polska 2019; 90, 11:662-666

\section{INTRODUCTION}

Puberty is a period of dynamic human development leading to sexual maturity. It is a transition period between childhood and adulthood, which takes place in several sequential stages controlled by neuroendocrine factors. It is characterized by the development of secondary and tertiary sexual characteristics and acceleration of linear growth, referred to as adolescent growth spurt [1]. The first external symptom of puberty in girls is breasts development (between 9-13 years of age). A relatively late event during puberty is menarche, which usually occurs about 1.2 to 1.3 years after reaching a maximum rate of linear growth (peak height velocity, PHV) [2]. In recent years the mean age at menarche in Poland ranged from 12.5 to 13 years $[3,4]$.

\section{METHODS FOR ASSESSING DEVELOPMENTAL AGE}

In both auxology and developmental gynecology, an important concept is developmental (biological) age, understood as progress toward a mature state, or, in other words, as the degree of physiological development of the organism. Significant interindividual variance exists for the level (magnitude of change), timing (onset of change), and tempo (rate of change) of biological maturation. 
An individual's developmental age may proceed at a different pace than the calendar age. It depends, to a large extent, on the genetic background, sex, environmental factors, body type, or ethnicity [5]. One of the most important reasons for assessing developmental age is to see how far it varies from chronological age. Estimation of differences between these two traits helps to identify signs of abnormal development, which may be precocious or delayed puberty [6]. Developmental age can be measured in several ways, including physical (morphological) maturity, stage of advancement in the development of secondary sex characteristics, skeletal maturity, and dental maturity. The physical maturity is assessed on the basis of height and weight. However, a more precise method of assessing physical maturity is the estimation of height velocity [7]. An informative marker of physical maturity during adolescence is both the age of onset of adolescent growth spurt (Age at Take Off, ATO), i.e. the moment when velocity of body height growth is the smallest, and the age when velocity of body height growth is the highest (Age at Peak Height Velocity, APHV) [2]. The take-off of the growth spurt (TO) in girls appears on average around 8-9 years, about 2 years earlier than in boys. Peak height velocity (PHV) occurs in girls aged 11.5 years, and in boys aged $13.5[2,3]$. In the assessment of developmental age during puberty, the markers of secondary sexual characteristics appear to be one of the most important. They are classified with the use of Tanner stages: breast stage in girls, genital stage in boys and pubic hair stage in both sexes [1]. Tanner stages (scores) describe the visible signs of sexual maturation. Stage one describes the absence of any symptoms of puberty, while stage five presents a fully developed form of assessed traits [5]. In girls, onset of puberty is defined as the first sign of breast development (B2 on the Tanner scale) and not pubic hair, because the latter does not necessarily herald activation of the gonads, and may be due to increasing secretion of adrenal androgens (adrenarche). Furthermore, in both gynecological practice and auxology, the age of the first menstruation, i.e. menarche, is an invaluable marker of the tempo of development. Skeletal age is usually estimated using hand-wrist radiograph, based on the appearance of individual bones or the degree of fusion of epiphyseal plate [8]. Another marker available for developmental age estimation is the dental age, based on tooth eruption or tooth mineralization assessed from dental radiographs. In each of the methods described, the child's status is compared with age-related norms. It is then assumed that the developmental age is the mean chronological age corresponding to her or his developmental status [7].

\section{CAUSES OF DELAYED PUBERTY IN GIRLS}

Delayed puberty in girls is defined as a lack of evidence of breast development by the age of 13 years and amen- orrhea 5 years after the start of the puberty with no full secondary sex features development [9]. It is also defined as the lack of signs of puberty at two standard deviations above the mean age for the general population [10]. Delayed puberty occurs in $3 \%$ of the population, more often in boys than girls. It may result from constitutional delay of puberty, hypogonadotropic or hypergonadotropic states, existing chronic diseases (as a secondary symptom), or intense physical exercise [11].

Delayed puberty is most often due to a functional defect in the production of gonadotropin-releasing hormone $(\mathrm{GnRH})$. Among the reasons for the abnormal secretion of $\mathrm{GnRH}$ from the hypothalamus is the constitutional delay of growth and puberty (CDGP), undernutrition or chronic illness. The result of GnRH deficiency is inadequate ovarian steroid secretion. Other causes of delayed puberty include a variety of hypothalamic, pituitary, and gonadal disorders [12].

In most cases, delayed puberty is caused by the constitutional delay of growth and puberty (CDGP) and is considered a temporary form of hypogonadotropic hypogonadism $[10,13]$. CDGD refers to a slower developmental tempo in children with no physical abnormalities causing the delay. These children start puberty late and are most often of short stature [5]. CDPG is 10 times more common in boys than girls and does not require advanced medical evaluation and treatment.

Many authors are emphasizing the influence of nutritional status and diet on estradiol concentration and puberty course. A common diagnosis for very slim girls with delayed puberty is functional gonadotropin deficiency. It is worth mentioning that this unusual thinness can result from either eating disorders, such as anorexia nervosa, or intense physical activity without enough caloric intake to maintain normal weight. Girls practicing: competitive swimming, ballet dancing, and gymnastics show the high risk of delayed menarche [6]. Intensive physical activity is connected with delayed puberty because of negative energetic balance, special diet, and corticotropic axis stimulation in increased stress leading to gonadoliberin excretion disturbances [13]. The relationship between the percentage of fat tissue and the dynamics of the puberty process has been demonstrated in girls $[3,14]$. Leptin secreted by adipose tissue is a key factor affecting the age of puberty onset since it has been shown to have a direct effect on the secretion of gonadotropins and gonadotropin releasing hormone (GnRH) [15]. Leptin receptors are identified in the hypothalamus, anterior pituitary gonadotropic cells and ovarian follicular cells. Abnormal leptin level in underweight girls with a low percentage of body fat generally result in amenorrhea and delayed puberty [16]. The same explanation is likely for girls who are very thin due to chronic illness. In gen- 
eral, the negative energy balance can disturb the pattern of pulsatile gonadotropin secretion leptin/neuropeptide $Y$ or using other neurotransmitters. Quantitative and qualitative nutritional status, BMI, fat tissue mass, and leptin blood level are important features in intense systemic and chronic disease state. A lot of chronic diseases are connected to delayed or arrest in the puberty stage which depends on the point at which the disease occurred. Malnourishment, or low BMI resulting from negative energy balance can cause the disturbance of pulsatile gonadoliberin secretion, as well as: a) gastrointestinal diseases: celiac disease should be considered when unexplained delayed of puberty and growth is observed, positive diagnosis should be confirmed by detection of transglutaminase antibodies and atrophic villi in jejunal biopsy; b) inflammatory bowel disease might be connected with delayed puberty in case of steroid therapy and weight loss; c) chronic lung diseases like cystic fibrosis can cause the same deficiencies which are caused mostly by malnourishment; $d$ ) chronic renal failure prior to transplantation or nephrotic syndrome sensitive to steroids; e) thalassemia major or sickle cell anemia can inhibit puberty by the deposition of iron in pituitary gland $[9,13]$.

Delayed puberty can also be caused by hypergonadotropic hypogonadism (primary ovarian failure), which may result from either karyotype abnormality (Turner syndrome) or autoimmune destruction of the ovaries, associated with conditions such as type 1 diabetes mellitus, hypothyroidism, Addison disease or hypoparathyroidism. The risk group of primary ovarian failure also includes girls undergoing total body irradiation or chemotherapy during the treatment of various forms of malignancies [9]. Hypogonadotropic hypogonadism is defined as lack of ability of proper production of gonadotropins - FSH and LH. This deficiency can be caused by isolated pituitary gonadotropic cells abnormality or coexistent with other pituitary cells changes concerning infundibulum or hypothalamus with a change in pulsatile secretion of gonadoliberin. Isolated idiopathic hypogonadotropic hypogonadism $(\mathrm{IHH})$ is often mistaken by CDGP because in both cases there is a low level of steroid hormones and gonadotropins. In CDGP, the response to gonadotropin agonists plays an important role in the differential diagnosis. Some girls with delayed puberty, usually with coexisting delayed growth and short stature (-2 SD on average height according to age) do not suffer from CDGP, but just a variation of development time. In this case, spontaneous beginning of puberty and acceleration of linear growth are observed. Hence, it is hard to differentiate between CDGP and $\mathrm{IHH}$, even if some symptoms can help with proper treatment choice. The main aim of the clinical, radiological and biological examination is to eliminate the somatic disease. It is important to differentiate the typical growth hormone deficiency. In the case of CDGP, short stat- ure and slow tempo of linear growth are well correlated with bone age, which is connected with delayed puberty but not chronological age. The growth hormone secretion might be low at a basal level whereas stimulation tests give positive results at a suboptimal level, which in fact corresponds to prepubertal period. The hormone level differences do not occur, which is confirmed by the tests of pituitary function. In this case systematic radiological examinations e. $g$. MRI do not show the signs of neoplastic process or infiltration to other organs [13]. Other causes of inappropriate gonadotropin secretion include, inter alia: organic direct gonadotropin deficiency, neoplastic origin of idiopathic hypogonadotropic hypogonadism (IHH), congenital gonadotropins deficiency (is connected with low FSH and LH level, compatible bone age and normal stature and normal karyotype; several genes connected with this condition have been identified), primary GnRH deficiency (after confirmation of $\mathrm{GnRH}$ deficiency, treatment with recombinant growth hormone will trigger puberty, which implies the need of IGF-1 treatment. IGF-1 is proved to enhance LH and FSH ovarian stimulation), Prader-Willi Syndrome, Laurence-Moon-Bardet-Biedl syndrome, Kallmann syndrome (uncommon in females, probably because the most common form, due to a defective KAL1 gene, is X-linked [9]. Delayed puberty may also be observed in patients with FSH or LH receptor coding gene mutation. Deactivating mutation of $\mathrm{FSH}$ receptor is connected with premature ovarian failure or primary amenorrhea. The size of ovaries is at a normal level and pathological examination shows multiple growing ovarian follicles. Several cases were observed in homozygotic XX females with primary amenorrhea, who developed sex features and elevated LH but normal FSH levels and ovarian vesicles with no corpus luteum. In case of absence of response on gonadoliberin stimulation test and pulsatile gonadoliberin application, we can consider gonadoliberin receptor gene mutation on chromosome 4 . There are reports about few autosomal recessive forms of isolated $\mathrm{IHH}$ with that kind of mutations. However, this phenotype occurs in various forms - from partial to full $[9,13]$. Only a few mutations inactivating FSH $\beta$ subunit was identified. The gene is situated in Xp21u in a female. One mutation presents with only partially developed secondary sexual characteristics and two with primary amenorrhea. DAX1 gene mutation (gene causing congenital adrenal dysplasia in case of X-linked inheritance). DAX1 is transcription factor from "orphan nuclear receptors" family, which take part in differentiation process of adrenal glands, hypothalamus, pituitary and gonads. Mutation of this gene connected with the $X$ chromosome in men leads to congenital hypoplasia with insufficiency in the neonatal period and delayed $\mathrm{IHH}$ that is manifesting during adolescence. There are reports about isolated $\mathrm{IHH}$ in women that might corre- 
spond to mild male $\mathrm{HH}$ connected with congenital adrenal hypoplasia [13].

The analysis of delayed puberty with hypogonadotropic hypogonadism of various etiologies reveals how important the molecular tests are in the process of diagnosis [17-20].

The hypergonadotropic hypogonadism with characteristic elevated FSH and/or LH level caused by ovarian failure requires rule out of female phenotype, uterine and ovarian functional tissue ultrasonographical verification, and karyotype assay $[9,13]$. The examples of such conditions are gonadal dysgenesis with a chromosomal aberration. The most frequent cause of primary ovarian failure is Turner syndrome in classic monosomy 45, XO form with female phenotype (poor growth, sexual infantilism, etc.). Swyer syndrome with $46, \mathrm{XY}$ karyotype is characterized by the female phenotype, female internal genital genitalia (Mullerian duct derivatives), normal or bigger height, gonadal dysgenesis, sexual infantilism, and primary amenorrhea. Ovarian dysgenesis with normal $46, \mathrm{XX}$ karyotype is characterized by diminished ovarian size and female phenotype. An interesting example of hypogonadotropic hypogonadism is Perrault syndrome as autosomal recessive ovarian dysgenesis coexisting with deafness. The diagnostic evaluation must include a detailed physical examination, height and bone maturation, measurements of general hematological and biochemical parameters, gonadotropins, sex steroids, prolactin, thyroid hormones, growth hormone and growth factors, and personal and familial antecedents [11].

It is important to conduct diagnosis per exclusionem diagnosis by exclusion - clinical examination with assessing the features of puberty, regular checkups, puberty progression) and biochemical examination including estradiol/testosterone, prolactin, GnRH antagonist, hCG level (hCG/hMG), hands X-ray, ultrasonography of uterine and ovaries, head CT or MRI if necessary.

\section{THE ROLE OF DEVELOPMENTAL AGE ASSESSMENT IN GIRLS WITH DELAYED PUBERTY}

The age at puberty depends on the interaction between genetic and environmental factors, which is the reason for the large phenotypic variance of its start and course. Thus, in the diagnosis of delayed puberty, the calendar age is not a sufficient measure of the level of advancement in biological development. The status of development of a child is usually assessed in relation to events that take place during the progress of growth. Hence, in the assessment of the biological age, various parameters are taken into account, such as bone age, age at menarche, body height, body mass, but also dental age [21]. While such markers of biological age as body height or weight, age at menarche or the level of development of secondary sexual characteristics assessed using the Tanner scale are known in gynecological practice, dental age is still used to a small extent. Many studies have demonstrated that sex hormones have an important role in osteogenic differentiation and hard tissue metabolism [22, 23]. They have an effect on facial and cranial base growth and are odontogenic [24]. However, their effects on dental development have not been clearly described in the literature. More than half a century ago, Garn et al. reported that children more advanced somatically or sexually were more advanced dentally, while children with retarded development showed delayed dental maturation but to a lesser degree than skeletal maturation [25]. The results were based on the systematic exploration of tooth formation in a variety of endocrine and non-endocrine developmental retardations and precocities. Two decades later, Demirjian et al. stated that the mechanisms controlling dental development do not depend on somatic and/or sexual maturity [26]. In their study, the age at which French-Canadian girls attained $90 \%$ of the dental development showed no significant relationships with the other maturity indicators.

In idiopathic precocious puberty, Roberts et al. found that dental ages were delayed in relation to their chronological age in children [27]. Conversely, the recent study by Lee et al. revealed early maturation of the mandibular teeth in girls with central precocious puberty [28]. As far as delayed puberty is concerned, Gaethofs et al. observed significant retardation of dental maturation in boys with CDGP. However, it should be emphasized that, the examined group was small and consisted of only 8 subjects [29].

As reminded by Różyło-Kalinowska et al., the assessment of dental maturity can be a valuable method for initial assessment of the level of skeletal maturity of a child [30]. However, it cannot be used as the only measure of development, especially in atypically developing patients, such as those with endocrine disorders, congenital diseases, or other signs and symptoms. Dental age is most commonly assessed with the use of the Demirjian method [31]. However, this method has some concerns. As mentioned above, the reference group was French-Canadian, and the possible effect of ethnicity was not taken into account. Another problem associated with the Demirjian method is that it does not include third permanent molars, therefore it cannot be used in young adults. According to Fudalej et al., the Demirjian method overestimates the dental age of Polish children of about 12 months [32]. Wites et al. stated that the dental age slightly proceeds the chronological age during puberty [33]. Zatylna et al. proved that the dental age assessed by Demirjian's method differs from the chronological age, more significantly in girls [34]. Dental maturation has been shown to be mildly but consistently delayed in patients with delayed development [35]. Therefore, in order to assess the abnormalities of the puberty process in a comprehensive way, apart from specialists in developmental 
gynecology, pediatrics, auxology or endocrinology, it would be worth including dentists who would add another marker of developmental age, which is dental age.

\section{SUMMARY}

Evaluation of developmental age during puberty using as many methods as possible (morphological age, secondary sexual characteristics, menarche age, bone age, dental age) allows the most comprehensive indication of signs of abnormal development, such as delayed puberty. Relationship between sexual maturation, skeletal age, dental age, general health, and a lifestyle support the need for collaboration between pediatricians, endocrinologists, pediatric gynecologists, dieticians and dentists in the management of irregularities of age at puberty.

\section{REFERENCES}

1. Marshall WA, Tanner JM. Variations in pattern of pubertal changes in girls. Arch Dis Child. 1969; 44(235): 291-303, doi: 10.1136/adc.44.235.291, indexed in Pubmed: 5785179.

2. Kaczmarek M. Adolescent growth and its relation to menarche, dental and somatic maturation. Anthropol Rev. 2002; 65: 27-42.

3. Durda-Masny M, Hanć T, Czapla Z, et al. BMI at menarche and timing of growth spurt and puberty in Polish girls - longitudinal study. Anthropol Anz. 2019; 76(1): 37-47, doi: 10.1127/anthranz/2019/0920, indexed in Pubmed: 30648186.

4. Gomula A, Koziel S. Secular trend and social variation in age at menarche among Polish schoolgirls before and after the political transformation. American Journal of Human Biology. 2017; 30(1): e23048, doi: 10.1002/ajhb.23048.

5. Hermanussen M. Auxology. Studying human growth and development. Germany Schweizerbart. ; 2013.

6. Malina Eb. Young Athletes Biological Psychological Educational Perspectives. Medicine \& Science in Sports \& Exercise. 1991; 23(9): 1116, doi: 10.1249/00005768-199109000-00022.

7. Cole TJ. The evidential value of developmental age imaging for assessing age of majority. Ann Hum Biol. 2015; 42(4): 379-388, doi: 10.3109/03014460.2015.1031826, indexed in Pubmed: 26133364.

8. Greulich W, Pyle S. Radiographic atlas of skeletal development of the hand and wrist. The American Journal Of The Medical Sciences. 1959; 238(3): 393, doi: 10.1097/00000441-195909000-00030.

9. Kaplowitz PB. Delayed puberty. Pediatr Rev. 2010; 31(5): 189-195, doi: 10.1542/pir.31-5-189, indexed in Pubmed: 20435710.

10. Vaaralahti K, Wehkalampi K, Tommiska J, et al. The role of gene defects underlying isolated hypogonadotropic hypogonadism in patients with constitutional delay of growth and puberty. Fertil Steril. 2011; 95(8): 2756-2758, doi: 10.1016/j.fertnstert.2010.12.059, indexed in Pubmed: 21292259.

11. Argente J. Diagnosis of late puberty. Horm Res. 1999; 51 Suppl 3: 95-100, doi: 10.1159/000053168, indexed in Pubmed: 10592450.

12. Crowley WF, Pitteloud N. Approach to the patient with delayed puberty. https://www.uptodate.com/contents/approach-to-the-patient-with-delayed-puberty.

13. Jarząbek-Bielecka G, Pisarska-Krawczyk M. Opóźnione dojrzewanie płciowe jako problem w ginekologii dziecięcej. In: Pisarska-Krawczyk M, Jarząbek-Bielecka G. ed. Zagadnienia interdyscyplinarne w ginekologii praktycznej. Kalisz Wydawnictwo PWSZ 2014: 69-93.

14. Frisch RE, Revelle R. Height and weight at menarche and a hypothesis of menarche. Arch Dis Child. 1971; 46(249): 695-701, doi: 10.1136/adc.46.249.695, indexed in Pubmed: 5118059.
15. Kaplowitz PB. Link between body fat and the timing of puberty. Pediatrics. 2008; 121 Suppl 3: S208-S217, doi: 10.1542/peds.2007-1813F, indexed in Pubmed: 18245513.

16. Shalitin S, Phillip M. Role of obesity and leptin in the pubertal process and pubertal growth--a review. Int J Obes Relat Metab Disord. 2003; 27(8): 869-874, doi: 10.1038/sj.ijo.0802328, indexed in Pubmed: 12861226.

17. Entrala-Bernal C, Montes-Castillo C, Alvarez-Cubero MJ, et al. Genetic diagnosis of idiopathic hypogonadotrophic hypogonadism: a new point mutation in the KAL2 gene. Hormones (Athens). 2014; 13(2): 280-285, doi: 10.1007/BF03401342, indexed in Pubmed: 24776628.

18. Jarząbek-Bielecka G, Sowińska-Przepiera E, Szafińska-Dolata A, et al Girls delayed puberty. Pediatric Endocrinology. 2014; 13(3): 65-70, doi: 10.18544/ep-01.13.03.1496.

19. Jarząbek-Bielecka G, Sowińska-Przepiera E, Szafińska-Dolata A, et al. Hipogonadyzm hipogonadotropowy jako przyczyna opóźnionego pokwitania dziewcząt. Endokr Pediat. 2014; 13(4): 41-45.

20. Jarząbek-Bielecka G, Drosdzol-Cop A, et al. The hypogonadism and delayed puberty in childhood and adolescent gynecology. Archives of Perinatal Medicine. 2017; 23(4): 229-235.

21. McKenna $\mathrm{CJ}$, James $\mathrm{H}$, Taylor JA, et al. Tooth development standards for South Australia. Aust Dent J. 2002; 47(3): 223-227, doi: 10.1111/j.18347819.2002.tb00333.x, indexed in Pubmed: 12405462.

22. Bland R. Steroid hormone receptor expression and action in bone. Clin Sci (Lond). 2000; 98(2): 217-240, indexed in Pubmed: 10657279.

23. Riggs BL, Khosla S, Melton LJ. Sex steroids and the construction and conservation of the adult skeleton. Endocr Rev. 2002; 23(3): 279-302, doi: 10.1210/edrv.23.3.0465, indexed in Pubmed: 12050121.

24. Kim SM, Lee BN, Koh JT, et al. The effect of chlormadinone acetate on odontogenic differentiation of human dental pulp cells: in vitro study. BMC Oral Health. 2017; 17(1): 89, doi: 10.1186/s12903-017-0379-0, indexed in Pubmed: 28549486.

25. Garn SM, Lewis AB, Blizzard RM. Endocrine factors in dental development. J Dent Res. 1965; 44: SUPPL:243-SUPPL:258, doi: 10.1177/00220345650440012001, indexed in Pubmed: 14242328.

26. Demirjian A, Buschang PH, Tanguay $\mathrm{R}$, et al. Interrelationships among measures of somatic, skeletal, dental, and sexual maturity. Am J Orthod. 1985; 88(5): 433-438, doi: 10.1016/0002-9416(85)90070-3, indexed in Pubmed: 3864376.

27. Roberts MW, Li SH, Cutler GB, et al. Dental development in precocious puberty. J Dent Res. 1985; 64(8): 1084-1086, doi: 10.1177/00220345850640081301, indexed in Pubmed: 3860542.

28. Lee HK, Choi SH, Fan D, et al. Evaluation of characteristics of the craniofacial complex and dental maturity in girls with central precocious puberty. Angle Orthod. 2018; 88(5): 582-589, doi: 10.2319/112317-809.1, indexed in Pubmed: 29708396.

29. Gaethofs $M$, Verdonck A, Carels C, et al. Delayed dental age in boys with constitutionally delayed puberty. Eur J Orthod. 1999; 21(6): 711-715, doi: 10.1093/ejo/21.6.711, indexed in Pubmed: 10665201.

30. Różyło-Kalinowska I, Kolasa--Rączka A, Kalinowski P. Relationship between dental age according to Demirjian and cervical vertebrae maturity in Polish children. Eur J Orthod. 2011; 33(1): 75-83, doi: 10.1093/ejo/cjq031, indexed in Pubmed: 20558591.

31. Demirjian A, Goldstein H, Tanner JM. A new system of dental age assessment. Hum Biol. 1973; 45: 221-227.

32. Fudalej P, Chrostowska E, Maciejewska A. Validity of nolla's and Demirjian's method of dental age assessment in children with a normal craniofacial structure. Czas Stomatol. 2007; 11: 744-751.

33. Wites $M$, Kalukin J, Niżankowska-Jedrzejczyk $A$, et al. Prediction of the growth spurt based on panoramic radiograhps. J Stomatol. 2011; 64: 875-886.

34. Zatylna N, Rogowska K, Kozanecka A. Comparison of 6-12 year old girls' and boys' dental age using Demirijan's method. Dent Med Probl. 2013; 50(1): 64-70.

35. Pirinen S. Endocrine regulation of craniofacial growth. Acta Odontol Scand. 1995; 53(3): 179-185, doi: 10.3109/00016359509005969, indexed in Pubmed: 7572094. 